Address for correspondence: Luis A. Marcos, Stony Brook University Health Sciences Center School of Medicine, Internal Medicine, Division of Infectious Disease, 101 Nicolls Rd, HSC T 16, Rm 027J, Stony Brook, NY 11794, USA; email: luis.marcos@stonybrookmedicine.edu

\title{
Ross River Virus Seroprevalence, French Polynesia, 2014-2015
}

\section{Maite Aubry, Anita Teissier, Michael Huart, Sébastien Merceron, Jessica Vanhomwegen, Claudine Roche, Anne-Laure Vial, Sylvianne Teururai, Sébastien Sicard, Sylvie Paulous, Philippe Desprès, Jean-Claude Manuguerra, Henri-Pierre Mallet, Didier Musso, Xavier Deparis, Van-Mai Cao-Lormeau}

\begin{abstract}
Author affiliations: Institut Louis Malardé, Tahiti, French Polynesia (M. Aubry, A. Teissier, C. Roche, S. Teururai, D. Musso, V.-M. Cao-Lormeau); Centre D'épidémiologie et de Santé Publique des Armées, Marseille, France; and Unité Mixte de Recherche Sciences Economiques et Sociales de la Santé et Traitement de I'Information Médicale, Marseille (M. Huart, S. Sicard, X. Deparis); Institut de la Statistique de la Polynésie Française, Tahiti; and Institut National de la Statistique et des Études Économiques, Sainte Clotilde, Réunion (S. Merceron); Institut Pasteur, Paris, France (J. Vanhomwegen, S. Paulous, J.-C. Manuguerra); Direction Départementale de la Cohésion Sociale et de la Protection des Populations, Yonne, France (A.-L. Vial); Direction de la Santé de la Polynésie Française, Tahiti (A.-L. Vial, H.-P. Mallet); Université de La Réunion, Sainte Clotilde, France; and Unité Mixte de Recherche Processus Infectieux en Milieu Insulaire Tropical, Sainte Clotilde (P. Desprès)
\end{abstract}

DOI: https://doi.org/10.3201/eid2310.170583

Ross River virus (RRV), spread by Aedes and Culex mosquitoes, is the most commonly transmitted arbovirus in Australia. A serosurvey of blood donors in French Polynesia during 2011-2013 suggested that RRV circulated without being detected. We report RRV circulation in French Polynesia based on further screening of blood samples collected during 2014-2015.

$\mathrm{R}$ oss River virus (RRV), an alphavirus of the family Togaviridae, is an arbovirus transmitted by Aedes and
Culex mosquito species (1). Symptoms of RRV infections mainly consist of fever, arthralgia, and rash. RRV was first isolated in North Queensland in 1959 and has become the most common arboviral disease in Australia (2). RRV outbreaks were reported during 1979-1980 in Pacific Island countries and territories (PICTs) including Fiji, Cook Islands, American Samoa, and New Caledonia (1).

In French Polynesia (FP), a territory of the Pacific region with $\approx 270,000$ inhabitants, dengue virus (DENV) was the only arbovirus detected until identification of the Zika virus (ZIKV), then chikungunya virus (CHIKV), causing outbreaks during 2013-2014 and 2014-2015, respectively (3). Although RRV infections have never been reported in FP, a serosurvey of blood donors during 20112013 suggested that RRV has circulated without being detected (4). In this study, we report additional evidence of RRV circulation in FP based on further screening of blood samples collected during 2014-2015 and previously used for a ZIKV serosurvey (5).

We tested 3 groups of participants randomly sampled in FP for the presence of anti-RRV IgG by using recombinant antigen-based indirect ELISA (patent no.WO2012076715A1) and microsphere multiplex immunoassay (patent no. WO2013083847A2) (4,5). The first group consisted of 196 participants recruited during February-March 2014 in 8 of the most inhabited islands of the 5 FP archipelagos (archipelagos listed in parentheses): Tahiti and Moorea (Society), Rangiroa and Makemo (Tuamotu), Nuku Hiva and Hiva Oa (Marquesas), Rurutu (Austral), and Rikitea (Gambier). The second group included 700 participants recruited during September-November 2015 on the 2 most inhabited islands of FP: Tahiti and Moorea. The third group consisted of 476 schoolchildren recruited during May-June 2014 on Tahiti. The Ethics Committee of French Polynesia approved recruitment of participants and processing of blood samples (approval no. 60/CEPF-06/27/2013). We analyzed seroprevalence data by using the Fisher exact test, and considered $\mathrm{p}$ values $<0.05$ as statistically significant.

RRV seropositivity rates among participants sampled in the 5 archipelagos in 2014 ranged from 16\% to $49 \%$ (average $35 \%$ ), and were significantly different between the Society and Marquesas $(\mathrm{p}=0.036)$, Tuamotu and Marquesas $(\mathrm{p}=0.001)$, and Tuamotu and Austral-Gambier $(\mathrm{p}=0.002)$ Islands (Table). In the Society Islands, screening of additional participants in 2015 did not lead to a significant difference in RRV seroprevalence (18\%) compared with the 1 observed in the participants recruited in $2014(27 \%)(p=0.125)$. In contrast, RRV seroprevalence among schoolchildren (1\%) was significantly lower than in the general population from the Society Islands, during both 2014 and 2015 ( $\mathrm{p}<0.0001)$. We compared 2 groups in the general population in 2014 and 2015. Rates of participants whose samples were RRVseropositive and who were born or arrived in FP before 
Table. Seropositivity for Ross River virus among participants randomly recruited in French Polynesia from the general population during February-March, 2014 and September-November, 2015; and from schoolchildren during May-June, 2014*

\begin{tabular}{|c|c|c|c|c|}
\hline $\begin{array}{l}\text { Sampled population, time } \\
\text { of sampling, location of } \\
\text { sampling }\end{array}$ & $\begin{array}{c}\text { Median age } \\
\text { (range), } \mathrm{y}\end{array}$ & $\begin{array}{l}\text { No. seropositive/No. born or } \\
\text { arrived in French Polynesia } \\
\text { before } 1982 \text { (\% [95\% CI]) }\end{array}$ & $\begin{array}{l}\text { No. seropositive/No. born or } \\
\text { arrived in French Polynesia } \\
\text { after } 1982(\%[95 \% \mathrm{Cl}])\end{array}$ & $\begin{array}{c}\text { Total no. } \\
\text { seropositive/Total no. } \\
\text { tested }\left(\%\left[\begin{array}{lll}95 \% & \mathrm{Cl}\end{array}\right)\right.\end{array}$ \\
\hline \multicolumn{5}{|l|}{ General population } \\
\hline \multicolumn{5}{|l|}{ February-March 2014} \\
\hline Society Islands & 47 (13-77) & $9 / 29$ (31 [14-48]) & $4 / 20(20[11-40])$ & $13 / 49$ (27 [9-45]) \\
\hline Tuamotu Islands & $39(7-86)$ & $6 / 28(21[6-37])$ & $2 / 21(10[4-27])$ & $8 / 49$ (16 [6-26]) \\
\hline Marquesas Islands & $45(10-82)$ & $15 / 32(47[30-64])$ & $9 / 17$ (53 [29-77]) & $24 / 49$ (49 [36-62]) \\
\hline $\begin{array}{l}\text { Austral-Gambier } \\
\text { Islands }\end{array}$ & $38(7-84)$ & $15 / 26(58[39-77])$ & $8 / 23(35[15-54])$ & $23 / 49$ (47 [35-59]) \\
\hline Total & $41(7-86)$ & $45 / 115$ (39 [30-48]) & 23/81 (2 [19-38]) & 68/196 (35 [27-43]) \\
\hline \multicolumn{5}{|l|}{$\begin{array}{l}\text { September-November } \\
2015\end{array}$} \\
\hline Society Islands & $43(4-88)$ & $77 / 397$ (19 [16-23]) & $46 / 303(15[11-19])$ & $123 / 700(18[15-21])$ \\
\hline \multicolumn{5}{|l|}{ Schoolchildren } \\
\hline \multicolumn{5}{|l|}{ May-June 2014} \\
\hline Society Islands & $11(6-16)$ & 0 & $6 / 476(1[0-2])$ & $6 / 476(1[0-2])$ \\
\hline
\end{tabular}

1982 (respectively, 39\% and 19\%) and thus potentially exposed to the last reported epidemic in the Pacific, were not significantly different from those who were born or arrived during or after 1982 (respectively, 28\% and 15\%).

Although no RRV outbreaks were reported in the PICTs after 1980, identification of RRV infections among travelers returning from Fiji between 1997-2009 suggested subsequent circulation of the virus in the Pacific $(6,7)$. In a serosurvey conducted in American Samoa in 2010, the finding that 63\% of participants born after 1980 and who had lived their whole lives in the territory were seropositive for RRV also supported this assumption (8). In our study, detection of RRV seropositive participants who were born or arrived in FP from 1982 shows that the virus probably circulated after the end of the 1979-1980 epidemic in the Pacific. This finding corroborates data previously obtained regarding blood donors (4).

In this study, we also provide evidence that RRV circulated in all archipelagos. The overall seroprevalence rate of $35 \%$ found in the general population in 2014 is consistent with the rate of $34.40 \%$ previously obtained in blood donors (4), with both groups of participants mainly including adults (median 41 and 36 years, respectively). The lower seroprevalence found in schoolchildren (median 11 years) compared with the general population in 2015 (median 43 years) is consistent with previous age-stratified studies showing that RRV seroprevalence increases with age (1). Nevertheless, because the seroprevalence observed in children is lower in FP than in endemic Australian areas (9), another reasonable explanation is that RRV circulated poorly in FP during the 16 years before the study. This observation is also supported by the small number of seropositive participants who arrived or were born after 2000 in FP, among the general population in $2014(3 / 18)$ and 2015 (0/54) (data not shown).

Increasing evidence that RRV circulated silently in several PICTs, in the absence of marsupial animal reservoirs (8), supports the need for enhanced laboratory and epidemiologic surveillance. Moreover, clinicians should be aware of the potential for RRV infections to occur. As illustrated with ZIKV and CHIKV, tropical islands are new hubs for emerging arboviruses and neither diseases nor places should be neglected (10).

\section{Acknowledgments}

We thank the staff from the Ministries of Health and Education of French Polynesia, the municipalities selected for the study, and the Institut Louis Malardé for their contribution in this work. We also thank all of the participants.

This study was partially funded by the Contrat de Projet Etat-Pays (convention no. 7331/MSS/DSP du 31/08/12 modifiée) and the French Government's Investissement d'Avenir Programme (Labex Integrative Biology of Emerging Infectious Diseases, IBEID, grant no. ANR-10-LABX-62-IBEID).

Dr Aubry is a research scientist at the Institut Louis Malardé, Tahiti, French Polynesia. Her research focuses on the epidemiology in the Pacific region and genetic evolution of various arboviruses including dengue, Zika, chikungunya and Ross River viruses.

\section{References}

1. Harley D, Sleigh A, Ritchie S. Ross River virus transmission, infection, and disease: a cross-disciplinary review. Clin Microbiol Rev. 2001;14:909-32. http://dx.doi.org/10.1128/ CMR.14.4.909-932.2001

2. Knope KE, Kurucz N, Doggett SL, Muller M, Johansen CA, Feldman R, et al.; National Arbovirus and Malaria Advisory Committee. Arboviral diseases and malaria in Australia, 2012-13: Annual report of the National Arbovirus and Malaria Advisory Committee. Commun Dis Intell Q Rep. 2016;40:E17-47.

3. Musso D, Cao-Lormeau VM, Gubler DJ. Zika virus: following the path of dengue and chikungunya? Lancet. 2015;386:243-4. http://dx.doi.org/10.1016/S0140-6736(15)61273-9

4. Aubry M, Finke J, Teissier A, Roche C, Broult J, Paulous S, et al. Silent circulation of Ross River virus in French Polynesia. Int J Infect Dis. 2015;37:19-24. http://dx.doi.org/ 10.1016/j.ijid.2015.06.005 
5. Aubry M, Teissier A, Huart M, Merceron S, Vanhomwegen J, Roche C, et al. Zika virus seroprevalence, French Polynesia, 2014-2015. Emerg Infect Dis. 2017;23:669-72. http://dx.doi.org/ 10.3201/eid2304.161549

6. Klapsing P, MacLean JD, Glaze S, McClean KL, Drebot MA, Lanciotti RS, et al. Ross River virus disease reemergence, Fiji, 2003-2004. Emerg Infect Dis. 2005;11:613-5. http://dx.doi.org/ 10.3201/eid1104.041070

7. Lau C, Weinstein P, Slaney D. Imported cases of Ross River virus disease in New Zealand - a travel medicine perspective. Travel Med Infect Dis. 2012;10:129-34. http://dx.doi.org/10.1016/ j.tmaid.2012.04.001

8. Lau C, Aubry M, Musso D, Teissier A, Paulous S, Desprès P, et al. New evidence for endemic circulation of Ross River virus in the Pacific Islands and the potential for emergence. Int J Infect Dis. 2017;57:73-6. http://dx.doi.org/10.1016/j.ijid.2017.01.041

9. Hawkes RA, Pamplin J, Boughton CR, Naim HM. Arbovirus infections of humans in high-risk areas of south-eastern Australia: a continuing study. Med J Aust. 1993;159:159-62.

10. Cao-Lormeau V-M. Tropical islands as new hubs for emerging arboviruses. Emerg Infect Dis. 2016;22:913-5. http://dx.doi.org/ 10.3201/eid2205.150547

Address for correspondence: Maite Aubry, Institut Louis Malardé, PO Box 30, 98713 Papeete, Tahiti, French Polynesia; email: maubry@ilm.pf

\section{Unrecognized Subclinical Infection with Tickborne Encephalitis Virus, Japan}

\section{Kentaro Yoshii, Reiji Kojima, Hiroshi Nishiura}

Author affiliations: Hokkaido University, Sapporo, Japan (K. Yoshii); Japan Self-Defense Forces Sapporo Hospital, Sapporo (R. Kojima); University of Yamanashi, Yamanashi, Japan (R. Kojima); Hokkaido University, Sapporo (H. Nishiura)

DOI: https://doi.org/10.3201/eid2310.170918

During early 2017, we conducted a seroepidemiologic investigation for tickborne encephalitis virus among $291 \mathrm{Ja}-$ pan Self-Defense Forces members in Hokkaido. Two (0.7\%) tested positive. Neither had clinically apparent symptoms after removing ticks.

$\mathrm{T}$ ickborne encephalitis virus (TBEV; genus Flavivirus, family Flaviviridae) persists in ticks and wild animals, including wild rodents and shika deer $(1,2)$. Geographically, the virus is widely spread across Eurasia and annually causes $\approx 10,000$ clinically apparent cases in humans (3). In Japan, tickborne encephalitis is notifiable. Two confirmed cases, both in Hokkaido in the northernmost prefecture, have been reported. The first confirmed case was serologically diagnosed in 1993 (4); the second case was confirmed in 2016.

During the 20-year gap between cases, serologic and virologic surveys of wild animals $(5,6)$ clarified that TBEV has been maintained in animal populations, especially in wild rodents in Hokkaido. Given the continued ecologic findings of virus activity in animals, it is plausible that humans have acquired TBEV infection, especially persons frequently exposed to ticks, including Japan Self-Defense Forces (JSDF) members of the Northern Army. We report the result from a pilot seroepidemiologic study of JSDF members conducted to determine the presence of unrecognized infections and to crudely measure the frequency.

We recruited 291 JSDF members who belong to the Northern Army and who received tick bites during ground activities (7). During their general health screening in February and March 2017, participants were asked to provide an additional $2 \mathrm{~mL}$ of serum for laboratory testing and to answer a questionnaire about the frequency of tick bites. We conducted neutralizing antibody testing using the virus isolated from Hokkaido in 1993 (4). We determined a serum sample to be TBEV positive if $\geq 50 \%$ plaque reduction compared with healthy human control serum was observed. We defined neutralizing titer as the reciprocal of the highest dilution of serum. To differentiate TBEV infection from Japanese encephalitis virus (JEV) infection, which occurs in southwestern Japan, we also conducted neutralization testing for JEV on all TBEV positive samples.

The Medical Ethics Committees at the Graduate School of Medicine, Hokkaido University and JSDF Sapporo Hospital approved this study. The research team explained to participants that the enrollment was voluntary and gave participants the right to withdraw. We obtained written informed consent from participants, and no names were assigned to serum samples or questionnaires.

Participants ranged in age from 35 to 54 years (mean 43.3 years). A total of $288(99.0 \%)$ of the 291 participants were men. Ninety-two (31.6\%; 95\% CI 26.5\%-37.1\%) participants appeared to have been bitten by ticks $\geq 1$ time during the previous 10 years; participants were bitten a mean of $1.4(\mathrm{SD} \pm 1.1)$ times. Two $(0.7 \%$; $95 \% \mathrm{CI}$ $0.0 \%-1.7 \%$ ) persons appeared to have been infected with TBEV; both were negative for JEV, the only other flavivirus in Japan. The TBEV-positive participants were men 42 and 48 years of age who had been bitten 3 and 1 times, respectively, within the previous 10 years (Table). Neither man complained of symptoms of TBEV infection, such as high-grade fever, headache, nausea, or paralysis after tick removal; however, the 48-year-old participant noted right knee joint pain, inguinal lymph node swelling, and lowgrade fever, which he attributed to the remaining body part of a tick. 